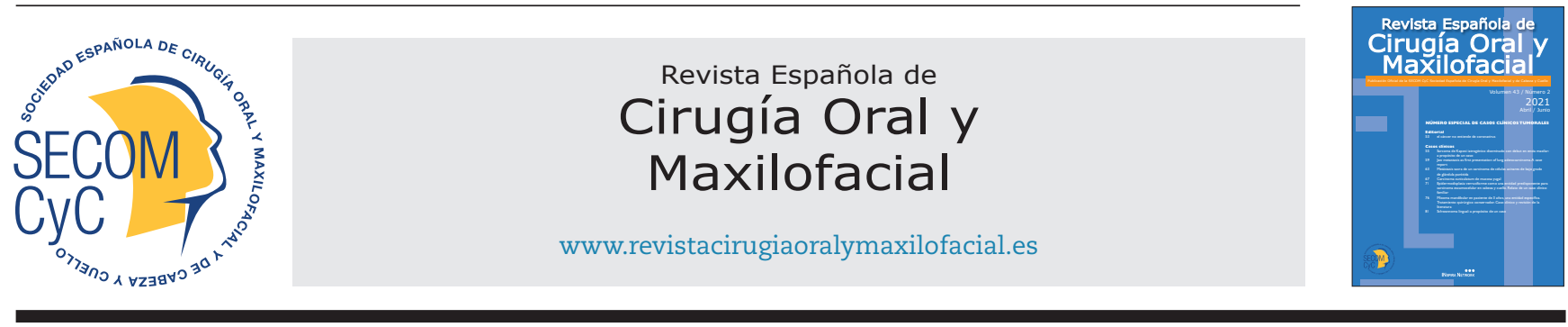

Caso clínico

\title{
Metástasis sacra de un carcinoma de células acinares de bajo grado de glándula parótida
}

\section{Celia Sánchez Gallego Albertos ${ }^{1 *}$, José Juan Pozo Kreilinger², Nicómedes Fernández Baíllo Gallego de la Sacristana ${ }^{3}$ y José Luis Cebrián Carretero ${ }^{4}$}

${ }^{1}$ Departamento de Cirugía Oral y Maxilofacial. Hospital Universitario La Paz. Madrid, España. ${ }^{2}$ Departamento de Anatomía Patológica. Hospital Universitario La Paz. Madrid, España. ${ }^{3}$ Departamento de Cirugía Ortopédica y Traumatología. Hospital Universitario La Paz. Madrid, España. ${ }^{4}$ Jefe de servicio de Cirugía Oral y Maxilofacial. Hospital Universitario La Paz. Madrid, España

INFORMACIÓN DEL ARTÍCULO

Historia del artículo:

Recibido: 21 de noviembre de 2020

Aceptado: 2 de febrero de 2021

Palabras clave:

Carcinoma de células acinares, cáncer glándula salivar, glándula parótida, metástasis.

\section{R E S U M E N}

El carcinoma de células acinares es una neoplasia de glándulas salivales poco común que generalmente cursa de manera indolente. La mayoría de los casos se presentan en las glándulas salivales mayores, principalmente la glándula parótida. Generalmente son neoplasias de bajo grado con una tasa de en torno al $20 \%$ de recidivas locales, y una tasa de metástasis de alrededor del $10 \%$, que pueden aparecer muchos años después del diagnóstico del tumor original. Las localizaciones más frecuentes de metástasis son los ganglios linfáticos cervicales, el hígado y los pulmones. Las metástasis óseas a nivel de la columna vertebral son extremadamente raras. En este artículo presentamos el caso de un paciente con un carcinoma de células acinares de glándula parótida derecha, que presentó metástasis a distancia a nivel del sacro 8 años después del tratamiento quirúrgico del tumor inicial.
Keywords:

Acinic cell carcinoma, salivary gland cancer, parotid gland, metastasis.

\section{Sacral metastasis of a low-grade acinar cell carcinoma of the} parotid gland

\section{A B S T R A C T}

Acinic cell carcinoma is an uncommon salivary gland neoplasm that is generally indolent. Most cases arise in the major salivary glands, mainly the parotid. Generally, they are lowgrade neoplasms with a $20 \%$ rate of local recurrences and about $10 \%$ rate of metastases which may appear many years after the initial presentation of the original tumour. The most frequent locations of the metastasis are the cervical lymph nodes, liver, and lungs. Metastases at the level of the spine are extremely rare. In this article, we report a case of a patient with an acinic cell carcinoma of the right parotid gland, who presented a distant metastasis at the level of the sacrum 8 years after surgical treatment of the initial tumour.

\footnotetext{
${ }^{*}$ Autor para correspondencia:

Correo electrónico: celiasga22@gmail.com (Celia Sánchez Gallego Albertos).

DOI: $10.20986 /$ recom.2021.1228/2020
}

1130-0558/@ 2021 SECOM CyC. Publicado por Inspira Network. Este es un artículo Open Access bajo la licencia CC BY-NC-ND (http://creativecommons.org/licenses/by-nc-nd/4.0/). 


\section{INTRODUCCIÓN}

Entre las neoplasias malignas primarias de la glándula parótida, el carcinoma de células acinares (CCA) representa del 1-6 \% de todos los tumores y del 10-15\% de todos los tumores malignos primarios ${ }^{1}$. Suele presentarse como una masa parotídea indolora de lento crecimiento y se considera un carcinoma indolente, de bajo grado, con una supervivencia general a los 5, 10 y 20 años del 97, 94 y $90 \%$, respectivamente ${ }^{2}$. La cirugía como tratamiento aislado generalmente proporciona un excelente control a largo plazo ${ }^{3}$. Sin embargo, a pesar de su patrón de crecimiento lento, su naturaleza asintomática puede llevar a un diagnóstico tardío, y en un subconjunto de pacientes se producen recidivas locorregionales y metástasis a distancia, pudiendo ocurrir estas incluso décadas después del diagnóstico y tratamiento iniciales ${ }^{4}$. En la literatura, la tasa de metástasis a distancia del CCA parotídeo está en torno al $10 \%$. Estos pacientes presentan una supervivencia de en torno al $22 \%$ a los 5 años ${ }^{2}$.

Presentamos un caso de un paciente de 67 años que presentó una metástasis sacra de un CCA parotídeo intervenido 8 años antes.

\section{CASO CLÍNICO}

Se trata de un varón de 67 años que acudió inicialmente a nuestro servicio presentando una tumoración a nivel preauricular derecho de 5 años de evolución, que había aumentado de tamaño progresivamente hasta alcanzar un diámetro de unos $5 \mathrm{~cm}$. La resonancia magnética reveló una tumoración intraparotídea derecha, marcadamente heterogénea en cuanto a su señal y realce, sin evidentes cambios infiltrativos sobre estructuras adyacentes. No se objetivaban adenopatías patológicas (Figura 1). El paciente fue sometido a una punción aspiración con aguja fina ecoguiada, en la que se objetivaron imágenes sugestivas de un tumor de tipo acinar, sin poder llegar a un diagnóstico definitivo mediante dicha técnica. Se decidió intervención quirúrgica para extirpación del tumor mediante una parotidectomía superficial derecha con preservación del nervio facial. El análisis histológico de la pieza quirúrgica evidenció un CCA de $3 \mathrm{~cm}$ de diámetro máximo (estadio patológico pT2), sin extensión extraparenquimatosa, de patrón predominantemente microquístico y con un denso estroma linfoide con centros germinales reactivos. No presentaba necrosis ni invasión perineural. El índice de proliferación Ki-67 fue del 5 \%. Los bordes de resección se encontraban libres de tumor. El postoperatorio transcurrió sin incidencias. Se decidió no administrar terapia adyuvante y se estableció un seguimiento en consultas cada 6 meses con resonancia magnética de control bianual.

Ocho años más tarde, el paciente comienza con lumbociatalgia izquierda con clínica neurológica incapacitante, motivo por el que es valorado en consultas de traumatología, solicitándose una resonancia magnética de columna lumbar, donde se objetivaba una gran tumoración a nivel sacro que destruía toda la porción inferior del sacro, extendiéndose a partes blandas de la región posterior, con sospecha radiológica principal de cordoma, y como segun-
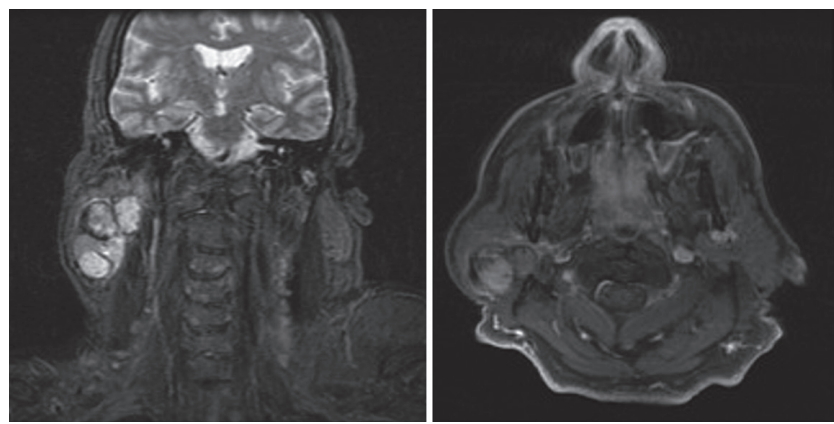

Figura 1. Resonancia magnética cervicofacial al diagnóstico. Secuencias en T2. Cortes coronal (izquierda) y axial (derecha).

da posibilidad diagnóstica un tumor de células gigantes convencional de hueso. Se realizó una punción guiada por tomografía computarizada de dicha lesión (Figura 2). En el análisis histopatológico se objetivó una tumoración epitelial con citomorfología acinar, patrón predominantemente microquístico (Figura 3) e inmunofenotipo positivo a pancitoqueratinas (AE1/AE3) y DOG-1, y negativo a brachyury y p63 (Figura 4), compatible con metástasis de CCA de glándula salival. No se objetivaron signos de recidiva local ni regional del tumor primario durante el seguimiento, que se mantiene en la actualidad.

Tras valoración conjunta en comité oncológico se desestimó intervención quirúrgica, iniciándose un esquema de quimioterapia y radioterapia paliativo.

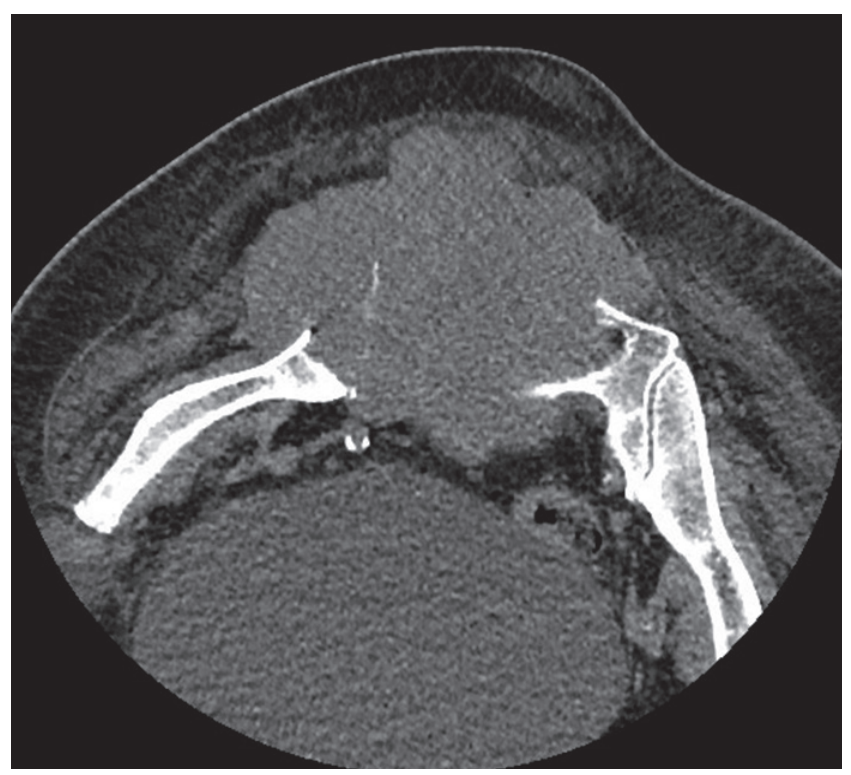

Figura 2. Corte axial de tomografía computarizada lumbar y pélvica. Se objetiva la gran tumoración sacra que destruye toda la porción inferior del mismo, extendiéndose hacia partes blandas de la región posterior. 


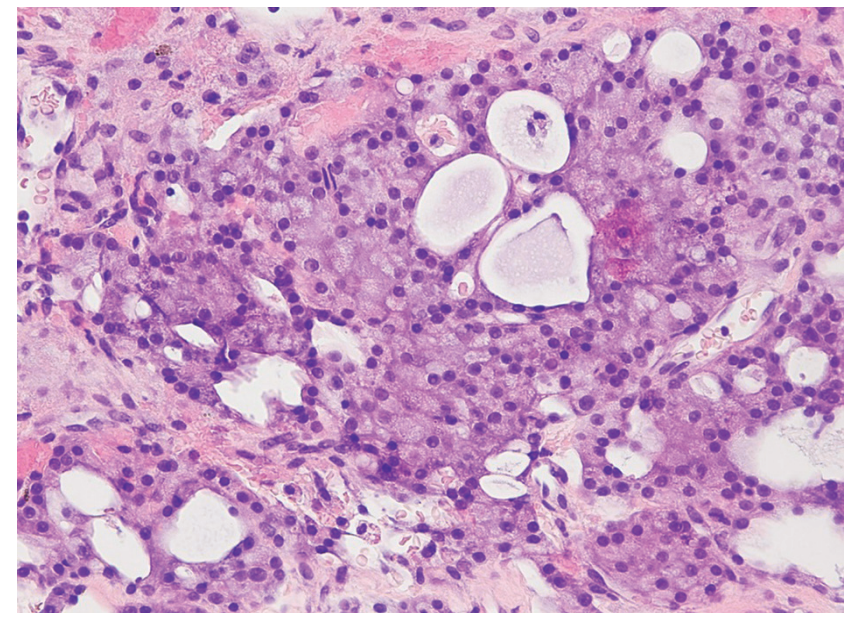

Figura 3. Tinción de hematoxilina y eosina a gran aumento (40x), que muestra una población monomorfa de células acinares de amplio citoplasma granular con un núcleo redondo y con formación de espacios quísticos de pequeño diámetro.
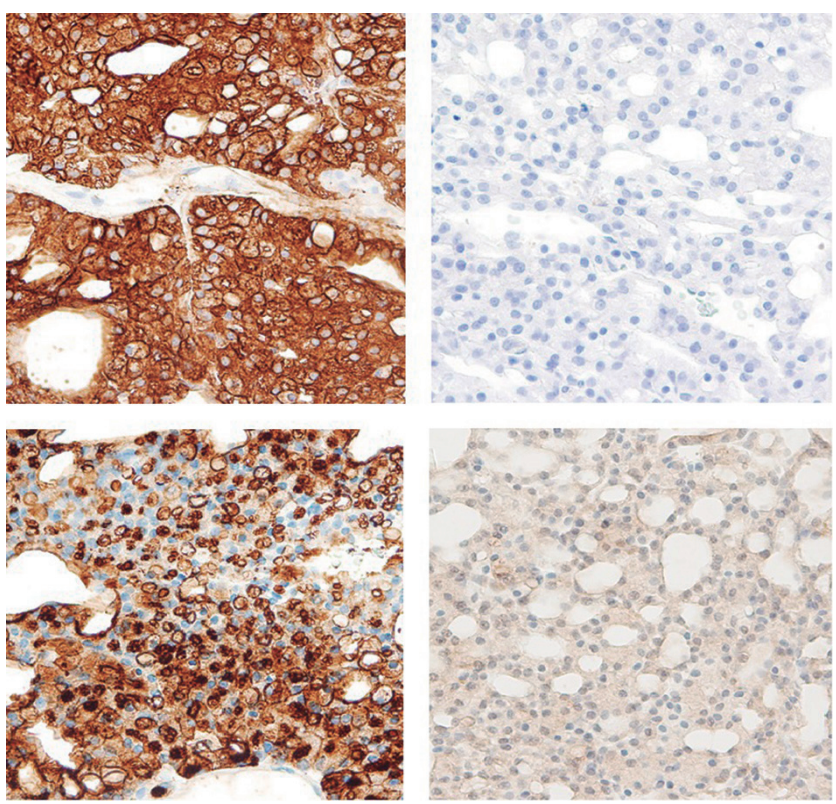

Figura 4. Por orden, de arriba a abajo y de izquierda a derecha, 1. AE1/AE3 (arriba, izquierda); 2. p63 (arriba, derecha); 3. DOG-1 (abajo, izquierda), 4. Brachyury (abajo, derecha).

\section{DISCUSIÓN}

El CCA es un tipo de tumor de las glándulas salivales poco común, que se consideró benigno hasta 1953, cuando Buxton demostró su capacidad para metastatizar y recidivar localmente $^{5}$. A pesar de ello se considera un tumor maligno de bajo grado. La tasa de supervivencia se ve afectada por la progresión de la enfermedad y la clasificación histopatológica.
Patel y cols. ${ }^{2}$ analizaron 1129 casos de CCA y los resultados de este estudio fueron significativos. Los pacientes con enfermedad localizada tenían tasas de supervivencia a 5, 10 y 20 años del $100 \%$, del $99,15 \%$ y del $94,37 \%$, respectivamente. Por otro lado, los pacientes con metástasis a distancia tenían tasas de supervivencia a 5, 10 y 20 años del 59,24\%, del 31,52\% y del $21,99 \%$, respectivamente. Los pacientes con tumores bien diferenciados tenían tasas de supervivencia a 20 años del $97,79 \%$ y los pacientes con tumores moderadamente diferenciados tenían una supervivencia a 20 años del 83,33\%. Sin embargo, los pacientes con CCA pobremente diferenciado tenían tasas de supervivencia a 20 años del 38,06\%.

Aproximadamente el $20 \%$ de los pacientes con diagnóstico de CCA de bajo grado experimentará recidiva local y el $10 \%$, metástasis a distancia, en contraste con los tumores de alto grado en los que el $33 \%$ recidivará localmente y el $46 \%$ dará lugar a metástasis a distancia, en muchos casos años después del diagnóstico inicial del tumor ${ }^{2,4}$. Los tumores de alto grado se definen como aquellos que presentan más de 2 mitosis por cada 10 campos de alta potencia y/o presencia de necrosis tumoral, mientras que el grado bajo indica una falta de cualquiera de las características ${ }^{4}$. Lo peculiar de nuestro caso clínico es que el carcinoma que presentaba nuestro paciente era un CCA de bajo grado (ausencia de necrosis, sin extensión extraparenquimatosa, índice de proliferación celular ki67 $<5 \%$, ausencia de invasión perineural). El hecho de que nuestro paciente desarrollase una metástasis a nivel de sacro 8 años después del diagnóstico y tratamiento quirúrgico del tumor inicial es tremendamente infrecuente.

En la cohorte de estudio de Ali y cols., 6 pacientes de una cohorte de 55 tratados mediante parotidectomía superficial o total por un CCA de glándula parótida desarrollaron metástasis pulmonares. Estos autores encontraron que los factores que se correlacionaron con el desarrollo de enfermedad a distancia fueron la clasificación T4, la diferenciación de alto grado y la presencia de invasión macroscópica del nervio facial ${ }^{6}$. A diferencia de este estudio, el caso que presentamos era un carcinoma de $3 \mathrm{~cm}$ (pT2) de bajo grado, lo cual hace aún más rara la aparición de metástasis a distancia. En un estudio recien$t^{7}$, los autores no encontraron ningún factor clinicopatológico que se correlacionase significativamente con los eventos de muerte, y el estadio TNM fue el único parámetro asociado significativamente con la recurrencia de la enfermedad.

Como ocurre con otros tumores malignos de parótida, rara vez causan metástasis esqueléticas distantes. La peculiaridad de nuestro caso fue la presencia de una metástasis ósea, originada por un CCA pT2 de bajo grado. Se ha descrito en la literatura algún caso de metástasis ósea de este tipo de tumor ${ }^{8,9}$. No obstante, Sessa y cols. describen una metástasis iliaca tras un CCA parotídeo recidivado desdiferenciado, y Khelfa y cols. describen metástasis múltiples (entre ellas óseas) tras un CCA parotídeo de gran tamaño, que se consideró irresecable y que recibió radioterapia como tratamiento inicial, con intención curativa.

\section{CONCLUSIONES}

El CCA es un tumor infrecuente que afecta principalmente a las glándulas salivares, fundamentalmente a la glándu- 
la parótida. Se consideran tumores de bajo grado y la tasa de metástasis a distancia es inferior al $10 \%$, produciéndose principalmente a nivel pulmonar. Este caso clínico de CCA en glándula parótida con metástasis solitaria en sacro confirmada histológicamente es, hasta donde sabemos, el primer caso descrito en la literatura.

\section{B I B L I O G R A F Í A}

1. Kim SA, Mathog RH. Acinic cell carcinoma of the parotid gland: a 15-year review limited to a single surgeon at a single institution. Ear Nose Throat J. 2005;84(9):597-602. DOI: 10.1177/ 014556130508400915.

2. Patel NR, Sanghvi S, Khan MN, Husain Q, Baredes S, Eloy JA. Demographic trends and disease-specific survival in salivary acinic cell carcinoma: an analysis of 1129 cases. Laryngoscope. 2014;124(1):172-8. DOI: 10.1002/lary.24231.

3. Vander Poorten V, Bradley PJ, Takes RP, Rinaldo A, Woolgar JA, Ferlito A. Diagnosis and management of parotid carcinoma with a special focus on recent advances in molecular biology. Head Neck. 2012;34(3):429-40. DOI: 10.1002/hed.21706.

4. Gomez DR, Katabi N, Zhung J, Wolden SL, Zelefsky MJ, Kraus DH, et al. Clinical and pathologic prognostic features in acinic cell carcinoma of the parotid gland. Cancer. 2009;115(10):2128-37. DOI: 10.1002/cncr.24259.

5. Buxton RW, Maxwell JH, Branch AJ: Surgical treatment of epithelial tumors of the parotid gland. Surg Gynecol Obstet. 1953;97:401-16.

6. Ali SA, Kovatch KJ, Yousif J, Gupta S, Rosko AJ, Spector ME. Predictors of distant metastasis in acinic cell carcinoma of the parotid gland. World J Clin Oncol. 2020;11(1):11-9. DOI: 10.5306/wjco.v11.i1.11.

7. Park YM, Yoon SO, Kim JH, Kang MS, Kim DH, Koh YW, et al. Comprehensive analysis of clinicopathologic factors predictive of an unfavorable prognosis in patients with acinic cell carcinoma of the parotid gland. Clin Exp Otorhinolaryngol. 2021;14(1):108-15. DOI: 10.21053/ ceo.2019.01550.

8. Sessa S, Ziranu A, di Giacomo G, Giovanni A, Maccauro G. A rare case of iliac crest metastasis from acinic cell carcinoma of parotid gland. World J Surg Oncol. 2014;12(1):48. DOI: 10.1186/1477-7819-12-48.

9. Khelfa Y, Mansour M, Abdel-Aziz Y, Raufi A, Denning K, Lebowicz Y. Relapsed acinic cell carcinoma of the parotid gland with diffuse distant metastasis. J Investig Med High Impact Case Rep. 2016;4(4):232470961667474. DOI: $10.1177 / 2324709616674742$. 